\title{
A Tale of Two Conflicts
}

On Pauline Kleingeld's New Reading of the Formula of Universal Law

Prof. Jens Timmermann

University of St Andrews

School of Philosophy

St Andrews, Fife, KY16 9AJ

United Kingdom

jt28@st-andrews.ac.uk 


\section{A Tale of Two Conflicts}

\section{On Pauline Kleingeld's New Reading of the Formula of Universal Law}

1. Introduction. Pauline Kleingeld's “Contradiction and Kant's Formula of Universal Law", published in this journal in 2017, presents a powerful challenge to a highly influential reconstruction of Kant's ethical theory. This reconstruction can be characterised as follows: ${ }^{1}$ The categorical imperative tells us to act only on those maxims that we can without contradiction will as universal laws; the contradiction characteristic of flouting it is practical, not a contradiction in the ordinary sense of the word; it is to be found in the world of the universalised maxim; and this contradiction can occur in two guises, as a contradiction that arises when we seek to conceive of the world governed by the universalised principles, produced by maxims that fall foul of 'strict' or 'perfect' duty, or as a contradiction in willing such a world, generated by maxims that violate 'wide' or 'imperfect' duty.

Kleingeld breaks ranks by highlighting what she calls the 'condition of simultaneous compossibility', or 'simultaneity condition' for short, i.e. the requirement that we must be able, without contradiction, to will our maxim and simultaneously or at the same time will that it be a universal law. On her account, the relevant contradiction is 'volitional'. It is located not in the world of the universalised maxim but rather within the agent's conflicted will. Her proposal, she argues, is both philosophically preferable and more faithful to Kant's text. In particular, it is thought to help us make better sense of his repeated claims that the will that adopts an immoral maxim is in conflict with itself, or that an immoral maxim entails a self-contradiction. Moreover, she rejects the terminology of the standard view - 'universalisation', 'contradiction in conception' and 'contradiction in the will' - as misleading.

In what follows, I shall argue that Kleingeld is right to emphasise the simultaneity condition, even though she subtly misconstrues its role; and that the standard terminology is indeed somewhat unfortunate. But in the final analysis, her reading should be seen as a supplement to the standard account, not as its rival. It redirects our attention from one kind of conflict (the contradiction that feeds into the normative constitution of moral prescriptions) to another (the antagonism within the will that is a distinguishing feature of violating moral laws). In so far as it aims at rejecting the standard reading we have reason to reject it.

2. The assumption of simultaneity. The simultaneity condition is at the heart of Kleingeld's proposal. It is not enough simply to imagine the scenario in which one's maxim is adopted by all. The categorical imperative demands of us that we be able to will, without contradiction, the envisaged maxim and simultaneously that that maxim be willed as a universal law. However, even though the universal law formula and many cognate versions of the categor-

1. Korsgaard traces this view back to the work of Onora O'Neill and Christine Korsgaard, cf. O’Neill, 1989, O'Neill, 2013 and Korsgaard, 1996. 
ical imperative include the word zugleich, there are two prominent exceptions (Kleingeld, 2017: 98-99).

The first is Kant's initial formulation at the end of Section I of the Groundwork: I must always act "in such a way that I could also [auch] will that my maxim should become a universal law" (AA 04:402.7-9, emphasis removed; similarly at AA 04:403.21 and 447.4). There is a temptation to drop the word auch in translation or to render it 'actually', since in Kant's time as in our own the particle often does not mean 'also' and is used merely for emphasis. But on this occasion it is Kant's way of introducing the simultaneity condition, and 'also' is the correct translation. Kleingeld is right. As is clear from the illustration of the fraudulent promise, Kant does not wish to say that the agent cannot will the lying promise. Such a promise may well be in the agent's overall interest. The relevant question is whether he can 'also', 'simultaneously' or 'at the same time' want the underlying maxim to obtain as a universal law.

The second apparent exception is the first variant in Section II, which centres on the notion of a system of natural laws. We are to act as if the maxim of our action were to become 'by' or 'through' our will a universal law of nature (cf. AA 04:421.18-20). As this is far and away the most significant formulation of the categorical imperative in the the whole book, it would create serious problems for Kleingeld's interpretation if the simultaneity condition did not feature in it. She seeks to explain the omission by arguing that if a principle "is turned into a universal law 'through one's maxim', then it is no longer merely one's maxim but simultaneously a universal law" (Kleingeld, 2017: 110 fn. 48). This means, Kleingeld plausibly maintains, that the simultaneity condition is tacitly implied by the law-of-nature formula as well.

However, to strengthen her interpretation Kleingeld feels the need to introduce the additional claim that these two versions of the categorical imperative apply to cases where the maxim at stake is a maxim the agent already has - hence "my maxim" at AA 04:402.8-9 and "the maxim of your action" at AA 04:421.18-19 (cf. again Kleingeld, 2017: 110 fn. 48). But such expressions cannot refer to principles the agent has already adopted. ${ }^{2} \mathrm{He}$ is trying to determine the moral status of a potential or available maxim. ${ }^{3}$ And yet, the prospective character of the maxim poses no threat to Kleingeld's simultaneity condition. After all, the maxim in question would be a maxim embraced by the agent were he to act on it. Simultaneity is still implied.

3. The stages of practical deliberation. The maxim under moral consideration is thus a maxim the agent is free to adopt. The question is whether he should adopt the candidate maxim,

2. And thus already acted on - particularly where perfect duty is at stake, which prescribes acts rather than broad action types.

3. It would be very odd if some formulations of the categorical imperative were to refer to maxims already adopted, others to maxims merely under consideration. 
whether he would be morally justified in acting on it, or - since Kant famously equates the will with practical reason ${ }^{4}$ - whether it deserves rational approval. There is, perhaps, a presumption that it does, since a maxim is a rule or principle and therefore a product of reason. Let us try to understand the process that leads to formulating a possible maxim.

Practical deliberation is triggered by inclination, i.e. by sensibility (cf., e.g., AA 05: 146.34). There is often considerable uncertainty. It can be unclear how an inclination is best realised; whether the object it favours will actually make us happy; and which inclinationbased object we should prefer if there are several candidates. That is how we come to assess our actions in normative terms. We no longer simply choose what we find immediately agreeable. We ask ourselves the question what would be in our long-term interest. ${ }^{5} \mathrm{~A}$ maxim is first formulated as a result of prudential, means-ends reasoning. ${ }^{6}$ At this early stage, it is an instrumental rule I am inclined to adopt as a subjective principle of action (a maxim) on the grounds that it appears to be best for me overall. It contains a certain generality because, if valid, it must be valid for all agents who find themselves in relevantly similar situations, my past and future self included. But this rule-like generality should not be confused with the universality of moral laws.

Let us use Kant's own favourite example. ${ }^{7}$ I am in financial difficulties and, after considering my options, consider obtaining money by means of a fraudulent promise a feasible course of action. The deliberative process is driven by inclination. The candidate maxim is a product of reason. ${ }^{8}$ As such, it must be justified tout court. It is one thing to ask whether an action is in my interest, and an entirely different question whether it is conclusively endorsed by practical reason. The fact that instrumental reason favours a maxim does not entail that pure practical reason does - or, what comes to the same thing, that all things considered the maxim secures rational approval. ${ }^{9}$

In the course of thinking about my situation, I successively take up two distinct practical standpoints, the limited perspective of prudential deliberation and the overall perspective of pure practical reason. Judged by the standards of the former, it is rational to make the

4. To be precise, the will is the capacity to act on rational principles, which in a finite being assumes the guise of imperatives; cf. AA 04: 412.29-30.

5. The maxim of fraudulent promises that is soon to be subjected to the categorical imperative is explicitly named a "maxim of prudence" at AA 04: 402.37-403.1.

6. Naturally, we also need to resort to problematic imperatives or 'rules of skill'. In practice, there can be no sharp distinction between technical and prudential deliberation.

7. Cf. AA 04: 402.16-403.17 and at AA 04: 422.15-36.

8. It therefore embodies a claim to generality. If it is a good rule for me to act on under present circumstances it must also be a good rule for me or for others if we find ourselves in relatively similar circumstances.

9. When there is prima facie a clash between empirical practical reason and pure practical reason the latter wins unambiguously and without residue. From a rational point of view, there is then nothing to be said for the option advanced by empirical practical reason. As Kant puts it in the Critique of Practical Reason, when the two yield incompatible prescriptions reason is altogether on the side of duty (cf. AA 05: 93.5-6). 
lying promise. Success is somewhat uncertain, but it looks like my best bet. However, I reach this conclusion on the basis of antecedent desires. If this restriction is removed, I ask myself the question whether I can at the same time will that the maxim suggested by prudential calculation should become a universal law. This is the second, moral standpoint, the standpoint of pure practical reason.

Now, crucially, the imaginary world of the universalised maxim contains me, the agent (cf., explicitly, AA 04: 403.7). For, as Kant puts it in the Metaphysics of Morals, all others myself excepted - would not be all (cf. AA 06: 451.6). So, it is easy to see why Kant tends to say that one must be able to will the maxim also, at the same time or simultaneously. It is not, as Kleingeld assumes, to mark the conflict within the will (which does, no doubt, exist), but to mark the transition from one stage of rational deliberation to the other. The 'simultaneity condition' demonstrates that we take the maxim of prudential reasoning with us as we enter the world of universalisation to see whether we can also will from that new perspective. Inclination-based reasoning comes first. It is needed to formulate candidate maxims. We are not allowed to enter the realm of universality with an empty will.

So, the 'simultaneity condition' is important, and Kleingeld is right to let it take centre stage. But its primary function is slightly different from what she takes it to be. One might also say that passages like the following introduce a false dichotomy:

On existing interpretations, the relevant contradiction is located in, or seen as 'involved in', the conception or the willing of a world in which the maxim is a universal law. By contrast, if we read the FUL along the lines I propose, the relevant contradiction should be located between willing that the maxim be one's own action principle (as willed independently of or prior to its universalization) and willing that it be a universal law. (Kleingeld, 2017: 100)

For moral judgement, I transport myself into the world of universalisation; and I take with me the maxim I previously entertained on independent grounds. ${ }^{10}$ If I find that I cannot will it as a maxim adopted by all - myself trivially included - at all times ${ }^{11}$, I cannot rationally, consistently, legitimately etc. act on it. It is to this incongruity that we now turn.

10. Kleingeld rightly objects to the description of universalisation as the "willing of a world in which the maxim is a universal law" (e.g. Kleingeld, 2017: 100). What is at stake is not the willing of a world but the willing in such a world.

11. Universality is commonly understood as the requirement that a maxim be valid for all agents, or for myself as well as all other agents. Kleingeld here follows the majority view. But there is a second, equally important dimension: a universal maxim is one that is adopted by all agents at all times. A maxim with a best-before date would not be universal; and when we conceive of a world in which the maxim of, e.g., falsely promising obtains as a universal law, this is not a world in which from now on everyone possesses a maxim of making lying promises if it appears means-ends rational. It is a world in which it is human nature - not, as at present, a matter of choice - for human beings to behave in this way, i.e. they go through the motions of saying that they will repay the money in time even though they know it is unlikely to do the trick. This explains the assumption - duly noted by Kleingeld (Kleingeld, 2017: 103 and 106) - the maxim is known to obtain in that world. It is a known feature of human nature that people have a strong tendency to act in this manner. 
4. Practical contradiction in the world of universalisation. Kant employs the language of conflict (Widerstreit) or contradiction (Widerspruch, widersprechen) in three out of four illustrations of the law-of-nature formulation of the categorical imperative. In the first, it is (human) nature that would be self-contradictory if it contained the maxim of self-murder (AA 04: 422.13); in the second, it is said that the maxim of fraudulent promising cannot hold as a universal law of nature but "must necessarily contradict itself" (AA 04: 422.13); in the fourth, Kant argues that a will that decreed a maxim of non-beneficence as a universal law of nature "would conflict with itself" (AA 04: 423.32). The third example is the exception. ${ }^{12}$ There Kant says that the agent cannot possibly will or want that the maxim of not developing one's talents to be a universal law because, as a rational being, he wants all capacities within him to be developed since "they serve him ${ }^{13}$ for all sorts of possible purposes" (AA 04: 423.32); it is these purposes that the universalisation of the maxim would undermine. But the second and fourth illustrations also revolve around the purposes an agent seeks to realise. The universality of the maxim of false promising "would make the promise and the end one may pursue with it itself impossible" (AA 04: 422.33-34); and the universality of the maxim of nonbeneficence would create a conflict because the agent might need the help and benevolence of others, which in that world would not be forthcoming (AA 04: 423.32-35).

Kleingeld rejects Korsgaard's and O'Neill's distinctly practical notion of 'contradiction' (Kleingeld, 2017: 97). Her own volitional conflict is a contradiction in a more straightforward, quasi-logical sense of being committed to the candidate maxim and its negation at the same time. Yet the language of the Groundwork strongly suggests that the principal problem with immoral maxims is that universalisation runs counter to the will of the agent, to be precise: that it would make the candidate maxim means-ends irrational. This is immensely plausible since it was, as we saw above, instrumental reason that recommended the maxim at a prior deliberative stage.

Let us return to Kant's example of the lying promise. I am, upon reflection, inclined to make someone else believe, by expressing an intention I do not intend to realise, that I will pay him back at a later date the money that I now so urgently need. Would I be "content" (zufrieden, AA 04:403.5) that the principle that underlies this course of action should hold as a universal law, a law that applies to myself as well as to others? I would not. And the reason is that I would not be able successfully to act on my maxim in the world in which it is universally adopted. It would make the promise and its underlying purpose impossible.

12. Both examples Kleingeld discusses in detail - the false promise and indifference towards the plight of other people - concern duties to others. It is a worthwhile question whether the simultaneity requirements is equally essential in the constitution of duties we have to ourselves, particularly if - as, Joshua Glasgow (Glasgow, 2003) has argued - the universality of maxims at issue there is temporal, i.e. the question is whether I can consistently will my maxim to hold throughout my life, past, present and future.

13. The second edition adds: "and are given to him". 
The contradiction in the world of the universalised maxim appears to be decidedly practical. $^{14}$

5. Self-contradiction and the purposiveness of the will. The above picture of rational deliberation suggests that the self-contradictions Kant mentions in three out of four cases occur in the will of the agent as he takes up the point of view of unconditional universal reason. There is no worry that we lose "one side of this self-contradiction" (Kleingeld, 2017: 102) because the agent is a member of the world of the universalised maxim. There is, in addition, what Kleingeld calls a 'volitional' contradiction, a conflict within the will of the agent who decides to act on such a maxim. ${ }^{15}$ But we have to be careful because maxims and the will may not be in conflict with themselves in quite the same way. ${ }^{16}$ In fact, Kant rarely talks about self-contradictory maxims. He does so explicitly only in the second of the four illustrations (the fraudulent promise) and implicitly - via the notion of "a nature whose law it were to destroy life" (AA 04:422.8-11) - in the first. For the most part, he speaks of the will that is in conflict with itself, fails to harmonise with itself or contradicts itself. So, a self-contradiction of the maxim occurs only in cases in which the maxim cannot even be thought as a universal law, conventionally dubbed cases of 'contradiction in conception' ${ }^{17}$ It is only in these two cases that the purpose of the action is contained in the maxim itself. However, as the purpose of the maxim is a fortiori the purpose of the will that acts on the maxim, this also leads to a contradiction in the will in the world of universalisation, in the manifest sense that acting on the universalised maxim would thwart its own purpose.

That is why the standard way of contrasting 'contradictions in conception' and 'contradiction in the will' is misleading. All 'contradictions in conception' lead to a 'contradiction in the will', but not vice versa. That is why Kant says that the maxims of some actions "cannot even be thought without contradiction as a universal law of nature; let alone that one could will that it should become such" (AA 04: 424.4-6), and why the categorical imperative is formulated in terms of also or at the same time being able to will or want - rather than think - the maxim one is inclined to act on as a universal law or law of nature. ${ }^{18}$ What is

14. Kant is not fetishising promises. It is not that I cannot will the world because I am committed to the institution of promising as such. I would not be content because I would be unable to realise the end I intend, i.e. I would be unable to obtain the money I need, because obtaining it depends on making my interlocutor believe that I will do what I do not intend to do.

15. The immoral agent is committed to the particular maxim and, as a being endowed with pure practical reason, to its negation because he cannot will it as a universal law. We shall return to the tension within the agent's will in $\S 8$ below.

16. Kleingeld equates the two, see Kleingeld, 2017: 96.

17. There is, however, one passage that appears to create problems for this line of argument, Kant's summary at AA 04:437.6-9: "A will is absolutely good that cannot be evil, hence whose maxim, if made a universal law, can never conflict with itself." It is unlikely that Kant is talking about the categorical imperative of perfect duty here.

18. These two points are emphasised in Timmermann, 2007: 86. 
more, the contradiction in the will - in the inclusive sense - is a contradiction in a fairly ordinary sense: the will as imagined in the world of universalisation is committed to willing and to not willing the maxim. It is committed to willing the maxim because it was the will's sole piece of luggage as it entered the realm of pure reason; it is committed to its opposite because it soon turned out not to be means-ends rational. And this incongruity is reflected in the conflicted will of the agent who decides to act on that unsuitable maxim.

Kleingeld will no doubt object that this line of argument relies on ascribing to the human will substantive values or essential purposes, which is something she sees in O'Neill and Korsgaard and clearly finds disconcerting (Kleingeld, 2017: 93, 96, 102, 107, 110 and 113). But the categorical imperative is a prescriptive principle for a finite will, so it should not come as a surprise that it reflects the commitments of this will - particularly since there is, as a matter of fact, just one such commitment other than rational justifiability: the agent's own happiness. ${ }^{19}$ Let us bear this in mind as we turn to Kleingeld's discussion of Kant's argument against a principle of non-beneficence.

6. Beneficence, egoism and solipsism. Kleingeld provides a detailed reconstruction of the fourth and final illustration of the law-of-nature formulation. As she notes, Kant is less than explicit about the maxim at issue (Kleingeld, 2017: 107). The agent is someone who does not overstep perfect duties to others, he does not seek to make them unhappy, he does not even envy them (AA 04: 423.20-21). But he is unwilling to contribute anything to their welfare. Kleingeld takes this to be an expression of the agent's 'maxim of egoism', namely: "I shall never help others in need of assistance, but I shall want others to help me when I need their help to achieve my own ends" (Kleingeld, 2017: 107). A world populated by egoists of this kind is not impossible; but "it is contradictory for the ordinary egoist to will his maxim and simultaneously to will a world in which no one ever helps others in need of assistance" (Kleingeld, 2017: 108). Kleingeld also notes that the egoist is not committed to an ideal of personal self-sufficiency because he - selfishly - still wishes for the assistance of others, but she does not seem to consider such an ideal unrealistic. The egoist's selfishness seems to result from his maxim. That is why he is in trouble in a world in which help is not forthcoming because everyone is equally selfish.

It is, however, quite clear that selfishness is not part of the maxim of the non-beneficent agent as Kant conceives of it. ${ }^{20}$ It doesn't have to be. The maxim in question is not Kleingeld's maxim of egoism but rather a maxim of solipsistic indifference ("What's it to me?", AA 04: 423.19), which is motivated by the inevitable commitment to one's own happiness that

19. Instrumental reason is concerned with realising ends, so means-ends rationality cannot count as an end over and above the two ends to which the will is already committed. (That would be double counting.) That is why Kant calls instrumental imperatives 'analytic' - they do not introduce and end over and above those already contained in the will, see AA 04: 417.11.

20. I should like to thank Mark Timmons for pointing this out to me. 
all human beings share, and which must not be allowed to go unchecked. In fact, pure practical reason turns it on its head. This is exactly how Kant proceeds in his discussion of beneficence in the Doctrine of Virtue: "I want everyone else's benevolence (benevolentia) towards me; therefore I ought also to be benevolent towards everyone else" (AA 06:451.4-451.6). And a little later:

For every human being who finds himself in need wishes to be helped by others. But if he were to make known his maxim of being unwilling to assist others in turn when they are in need, i.e. to make it a universal permissive law, then everyone would likewise deny him assistance when he is in need himself, or at least would be warranted to deny it. (AA 06: 453.5-10)

Complete self-sufficiency is not an option for finite beings like us, though individual requirements and tolerance thresholds will differ. ${ }^{21}$ Unlike the Stoics, Kant was not blind to the essential vulnerability of humanity. Even the most self-sufficient person will want the assistance of others if things get bad enough; and it should not be too difficult for him to see that others need his help in situations in which he may not. Moreover, there is a manifest sense in which someone who is not prepared to help others while inevitably, unalterably hoping for their help is guilty of exceptionalism, which has long been considered a central element of Kant's conception of moral evil. ${ }^{22}$

7. A tale of two conflicts. The account of Kant's universalisation formulas presented so far suggests that a contradiction arises when the agent takes up the point of view of pure reason to determine whether an illegitimate maxim suggested by prudential deliberation can be willed as a universal law in a world that includes the agent. Moreover - serious worries about the standard terminology of contradiction notwithstanding - this kind of conflict appears to be the one that Christine Korsgaard has dubbed a 'practical' contradiction: a will placed in the world of the universalised maxim would contradict itself in the sense that a rule initially devised on prudential grounds ceases to be means-ends rational. But this is not Kleingeld's 'volitional contradiction', which does not arise in the world of the universalised illegitimate maxim but rather within the will of the agent who acts on it, between willing the maxim as the principle of one's action "as willed independently of or prior to its universalization" and willing the same principle as a universal law (Kleingeld, 2017: 100). Moreover, Kant clearly believed that something akin to Kleingeld's 'volitional contradiction' is distinct-

21. Moreover, it would be unfortunate if someone committed to an ideal of individual self-sufficiency could thereby opt out of the duty of beneficence.

22. What is more, Kleingeld is concerned that Kantian ethics in general and the impermissibility of her maxim of egoism in particular would render "any form of competition is morally impermissible" (Kleingeld, 2017: 108). But there is no need to be worried. First of all, as she herself notes, competition must be restricted by rules of peacefulness and fairness. But, secondly, we we engage in competitive activities, we just do what all other competitors are doing too: we are trying to get ahead. In many cases, the value of being competitive depends precisely on this fact - you would not want to 'win' a game if you are the only contestant. 
ive of immoral behaviour. There are, it seems, two distinct kinds of contradiction. On at least one occasion Kleingeld practically admits this by distinguishing the 'relevant' contradiction from another:

Furthermore, on the reading proposed above, the relevant contradiction - the volitional self-contradiction - is not the inconsistency in the conception of the maxim as a universal law. On the Volitional Self-Contradiction account, the fact that one's purpose is thwarted or that one's project is impossible when the maxim is a universal law does not constitute the relevant contradiction but rather produces it. We cannot will the maxim and simultaneously will that it be a universal law because the maxim cannot be a universal law. (Kleingeld, 2017: 107)

She actually calls the contradiction at the heart of her project the 'relevant' contradiction throughout.

8. From contradiction to antagonism. So, the primary achievement of Kleingeld's paper seems to be this: it directs our attention away from one conflict (the contradiction that arises in the world of the universalised maxim) to another (the contradiction that occurs within the will of the immoral agent). The first is constitutive of moral judgement; only agents who act contrary to their own, better moral judgment incur the second..$^{23}$ We do, however, need to make an adjustment that will take us a little further away from Kleingeld's interpretation. Kant denies that the 'volitional' contradiction is a contradiction proper. It comes about as the will takes up two distinct points of view and is therefore better characterised as an antagonism within the human will.

We have seen how the world of the universalised maxim can easily be interpreted as containing a self-contradiction of the maxim as long as we place the will that contains it in that very world. The maxim does not conflict with itself - it is rational - when viewed from the limited perspective of means-ends practical reasoning; it does conflict with itself - it is irrational - when viewed from the unrestricted perspective of universality that pure practical reason urges us to adopt. The perspective of the latter is authoritative for the former; an imperative emerges as a consequence; the immoral agent violates this very imperative; and this is the 'volitional contradiction' to which Kleingeld seeks to redirect our attention.

But we need to say more about the contradiction that arises in a finite, immoral will. Throughout Kleingeld argues that it is quasi-logical and more easily understood as an ordinary contradiction than that which Korsgaard attributes to the world of the universalised maxim. It consists in willing "that one act on the maxim oneself" and, at the same time, since its universalisation is impossible, "willing that no one does" (Kleingeld, 2017: 90, cf. 107). However, as we saw above, the conflict is also associated with two different perspectives:

The fact that Kant locates the relevant self-contradiction of the will between the 'private' and the 'general' or 'universal' perspective is important. For this suggests that

23. However, as we shall see below, a certain tension is present throughout. This is the tension of the moral ought. 
the self-contradiction of which Kant speaks in connection with the FUL should be understood in a parallel fashion, as a contradiction between willing a maxim as one's own private maxim and willing it as a universal law. (Kleingeld, 2017: 102)

And there's the rub. As we occupy two different points of view, there is - strictly speaking no contradiction between willing the maxim and not being able to will its universalised counterpart, i.e. willing that it not obtain as a universal law. ${ }^{24}$ Kant explicitly says so in the Groundwork. When we transgress duty, he says, we do not want our maxim to become a universal law; we want its opposite to remain generally in force so that we can make an exception in the interest of our own inclination (cf. AA 04:424.15-20). But that contradiction - a contradiction in the strict sense - arises only from the point of view of reason, i.e. in the world of the universalised maxim:

Consequently, if we considered everything from one and the same point of view, namely that of reason, we would find a contradiction in our own will, namely that a certain principle be objectively necessary as a universal law and yet subjectively should not hold universally, but allow of exceptions. (AA 04:424.20-25, emphasis not in original $)^{25}$

It is only then that Kant turns to Kleingeld's 'volitional' contradiction, which takes the two standpoints ${ }^{26}$ into account:

But since we consider our action at one time from the point of view of a will that entirely conforms with reason, but then just the same action also from the point of view of a will affected by inclination, there is actually no contradiction here, but rather a resistance of inclination to the prescription of reason (antagonismus), by which the universality of the principle (universalitas) is transformed into a mere general validity (generalitas), and by this the practical rational principle is meant to meet the maxim halfway. (AA 04:424.25-33, emphasis not in the original)

I can will the lying promise without contradicting myself; it may well be means-ends rational. I cannot will the corresponding maxim as a universal law because it would make effect-

24. Arguably, the will would unable to contain an ordinary contradiction, i.e. the willing of a maxim and its negation from one and the same perspective. That is precisely why reason baulks at immoral maxims in the universalisation scenario.

25. Kleingeld quotes the assertion that there would be "a contradiction in our own will" twice (Kleingeld, 2017: 96 and 102), but she fails to mention that it arises only when we consider things from one perspective only, i.e. within the world of the universalised maxim (rather than within the will that acts immorally with its two standpoints, which she correctly identifies as the particular and the universal, see Kleingeld, 2017: 101).

26. There are two functionalities within the will, the universal and the particular, later called Wille (the legislative will or judgement) and Willkür (the elective will or faculty of choice). Kleingeld's volitional contradiction is a tension between the two. Maxims are associated with the latter, but they need to be held up against the former. This distinction is not an invention of the 1790s. It is clearly stated in the Powalski lecture notes, which date from around the early 1780s (cf. Timmermann, forthcoming). We learn that "we have a twofold will": "a will of the understanding, necessitated by many practical laws" and "an animal will, and there we are not, it is true, necessitated by stimuli, but we are still impelled [impellirt] by them" (XXVII 123.19-22), a faculty of choice (Willkür) that is affected but not determined by sensibility. The human will is internally divided: "Willkür", Powalski says, "is distinct from Wille. Willkür is the kind of will that is practical, whereas Wille is not practical" (XXVII 140.8-10). 
ive promising impossible, so I have to will its opposite. That has normative implications and is thus reflected in the conflicted nature of the immoral human will as a whole, which can act on a maxim and at the same time be rationally committed to its negation. Because this involves two distinct perspectives, Kant is unwilling to call it a contradiction. So should we. ${ }^{27}$

9. Conclusion. Kleingeld's "Contradiction and Kant's Formula of Universal Law" is an immensely thought-provoking paper. It forces us to direct our attention to the question of what exactly formal versions of the categorical imperative ask us to do, and to the problem generated if we fail to obey. But the implications of this shift of focus are less revisionist that Kleingeld tends to assume. We do not need to abandon the terminology of contradictions 'in conception' and 'in the will' as long as we bear in mind that every contradiction in conception necessitates a contradiction in the will, but not vice versa - hence the wording of the categorical imperative as a criterion of duty in general in terms of maxims that I can at the same time will. Nor is there any need to abandon the language of 'universalisation' as long as we note that the agent himself, with his proposed maxim, is a member of the world in which that maxim is a universal law, i.e. adopted by all agents at all times. There, the 'all' of universality really does mean 'all', the envisaged agent included. The question whether I can will the world of universalisation - whether pure practical reason approves or disapproves of my maxim - is decided by the agent in that world. Kleingeld's 'volitional' contradiction would not arise without it. So, we do not, in the end, need to adopt a new account of the contradiction that constitutes immorality, but we would be well advised also to reflect upon another inconsistency: Kant's 'antagonism' of inclination and the prescription of reason, which is Kleingeld's 'volitional contradiction' ${ }^{28}$

27. As was argued in $\S 5$, the self-contradiction must - a fortiori - be located in the world of universalisation.

28. I am grateful to audiences at the Universities of Keele and St Andrews for comments on earlier versions of this paper. Thanks are due to Sorin Baiasu, Alix Cohen, Simon Hope, David Hyder, Kristina Kersa, Stefano Lo Re, Janis Schaab, Mark Timmons, Michael Walschots and to my wife, Kate Moran. I am particularly indebted to Pauline Kleingeld for helping me kindly and patiently to find out where we agree and where we agree to differ. 
References

Glasgow, Joshua (2003). Expanding the Limits of Universalization: Kant's Duties and Kantian Moral Deliberations. Canadian Journal of Philosophy 33, 23-48.

Kleingeld, Pauline (2017). Contradiction and Kant's Formula of Universal Law. Kant-Studien 108, 89-115.

Korsgaard, Christine (1996). Kant's Formula of Universal Law. In Creating the Kingdom of Ends, 77-105. Cambridge: Cambridge University Press. First published in 1985.

O'Neill, Onora (1989). Consistency in Action. In Constructions of Reason, 81-104. Cambridge: Cambridge University Press. First published in 1985.

O'Neill, Onora (2013). Acting on Principle: An Essay on Kantian Ethics, second edition. Cambridge: Cambridge University Press. First edition 1975.

Timmermann, Jens (2007). Kant's "Groundwork of the Metaphysics of Morals": A Commentary. Cambridge: Cambridge University Press.

Timmermann, Jens (forthcoming). Emerging Autonomy: Dealing with the Inadequacies of the 'Canon of Pure Reason' (1781). In Stefano Bacin \& Oliver Sensen (Eds.), The Emergence of Autonomy. Cambridge: Cambridge University Press. 